\title{
Blind Rule-Following and the Regress of Motivations
}

\author{
Zachary Mitchell Swindlehurst \\ Australian National University \\ University of Otago
}

\begin{abstract}
Normativists about belief hold that belief formation is essentially rule- or norm-guided. On this view, certain norms are constitutive of or essential to belief in such a way that no mental state not guided by those norms counts as a belief, properly construed. In recent influential work, Kathrin Glüer and Åsa Wikforss develop novel arguments against normativism. According to their regress of motivations argument, not all belief formation can be rule- or norm-guided, on pain of a vicious infinite regress. I argue that the regress of motivations argument is unsuccessful: an appeal to the notion of blind rule-following, drawn from a plausible interpretation of Ludwig Wittgenstein's remarks on rule-following, stops the regress of motivations in its tracks.
\end{abstract}

\section{Introduction: Belief Normativism}

A recent strand of the rule-following considerations concerns the thought that belief formation is an essentially rule- or norm-guided activity. According to normativism about belief ('normativism' hereafter), certain norms are constitutive of or essential to belief: no mental state not guided by those norms counts as a belief, properly construed. ${ }^{1}$

One way of making sense of the slogan that belief 'aims at truth' (Williams 1973) is to hold that belief formation is essentially guided by a truth norm - a norm that links one's obligation to believe some proposition with the truth of that proposition:

(Truth) For all $S, p: S$ ought to believe that $p$ if and only if $p$ is true. ${ }^{2}$

The normativist holds that (Truth) - or something like it - is constitutive of belief: some mental state $M$ is a belief, rather than some other state, only if $M$ is essentially guided by (Truth). ${ }^{3}$ Thus, normativism seeks to partly distinguish belief from the other cognitive attitudes.

\footnotetext{
${ }^{1}$ Normativism has many defenders. Among them are Wedgwood (2002), Boghossian (2005), Shah and Velleman (2005), Whiting (2010), Fassio (2011), Gibbard (2012), and Nolfi (2015), to name a few.

2 (Truth) is perhaps obviously too strong, but we can simply assume it here. Bykvist and Hattiangadi (2007, 2013) offer criticism of (Truth) that centres on the norm's formulation. This issue has recently received much attention. See, e.g., Wedgwood (2013), Kalantari and Luntley (2013), Raleigh (2013), and Greenberg (2018).

${ }^{3}$ Not all normativists appeal to a truth norm. For instance, some hold instead that belief is essentially guided by a knowledge norm - a norm that links one's obligation to believe that $p$ with her knowing (or at least being in a position to know) that $p$. I discuss this issue in Swindlehurst (2020).
} 
In a recent series of influential works, Kathrin Glüer and Åsa Wikforss develop two novel arguments against normativism (Glüer and Wikforss 2009, 2010a, 2013, 2015). Much discussion has already focused on their no guidance argument. ${ }^{4}$ According to this argument, (Truth) cannot offer any guidance to a subject as to whether she ought to believe that $p$, since in order to determine whether the 'antecedent conditions' of the norm are satisfied, she must have already formed a belief as to whether $p$. A second, less frequently discussed argument is the regress of motivations argument, according to which not all belief formation can be rule- or norm-guided, on pain of a vicious infinite regress.

In this paper, I argue that the regress of motivations argument is unsuccessful. Glüer and Wikforss ('G\&W' hereafter) consider and reject an appeal to blind rule-following as a potential way out of the regress. On their view, blind rule-following involves a rejection of an intentional condition on rule-guidedness. Contrasting 'blind' with 'intentional' in this way means we fail to secure an important distinction between genuine rule-following, on the one hand, and mere conformity (or accordance) with a rule, on the other. But G\&W ignore an alternative conception of blind rule-following - one inspired by a reading of Ludwig Wittgenstein's (1953) remarks. According to this alternative reading, 'blind' contrasts not with 'intentional' but with 'based on interpretation': to say that some rule-following is blind is to say that, at the fundamental level, rule-following is not based on interpretation (McDowell 1984, 1993; Miller 2014, 2015, 2017). I will argue that this alternative conception of blind rule-following does not allow the regress of motivations to start and should not, in contrast to what G\&W go on to suggest, tempt us into an unsatisfactory philosophical quietism. ${ }^{5}$

I proceed as follows. §2 outlines the regress of motivations argument as G\&W present it. In $\S 3$, I reconstruct G\&W's argument to the effect that a non-intentional view of rule-following - a view they equate with blind rule-following - does not provide a way out of the regress of motivations and instead suggests an unsatisfactory philosophical quietism. In $\S 4$, I argue that the conception of blind rule-following according to which 'blind' contrasts with 'based on interpretation' does not allow the regress of motivations to get off the ground, drawing an analogy with a regress argument from Boghossian $(2008,2012)$ and Miller's (2015) critique of that argument. I conclude by noting that, unlike an appeal to the non-intentional view, an appeal to

\footnotetext{
${ }^{4}$ See, among others, Steglich-Petersen (2010, 2013), Engel (2013), Toppinen (2015), and Hlobil (2015).

5 Those who have already discussed G\&W's 'dilemma of regress and idleness' have not, as far as I can tell, connected the regress horn of the dilemma with the notion of blind rule-following. G\&W's regress arguments are discussed by Jarvis $(2012, \S 8)$, Hlobil $(2015, \S 5)$, Toppinen $(2015, \S 2)$, and Tracy $(2019, \S 3)$.
} 
blind rule-following does not suggest a quietist answer to the question of what secures the following/conforming distinction.

\section{The Regress of Motivations Argument}

According to the regress of motivations argument, not all belief formation can be rule- or normguided, on pain of a vicious infinite regress (G\&W 2009, 55-9; 2013, 94-7). G\&W begin with what they take to be an intuitive conception of rule-guidance - one that must accommodate a substantive distinction between following or being guided by ${ }^{6}$ a rule, on the one hand, and (merely) conforming to (or acting in accordance with) one, on the other. For example, you put one foot in front of the other in order to walk down a corridor. This does not mean you are being guided by the rule

(Corridor) When walking down a corridor, put one foot in front of the other!

Rather, putting one foot in front of the other is just something you typically do; you are merely acting in accordance with (Corridor), not being guided by it. So, how should we secure the distinction between genuine rule-guidance and mere accordance with a rule? G\&W rely on what they take to be a natural, intuitive picture of rule-guidance:

(Guidance) Some performance $A$ is guided by a rule $R$ if and only if (i) $R$ plays a certain role in $S$ 's motivation for $A$; and (ii) the role $R$ plays in $S$ 's motivation for $A$ is such that there will be a certain kind of intentional explanation for $A$ (G\&W 2013, 94).

The intentional explanation mentioned in (Guidance) involves some kind of acceptance of $R$ : 'This explanation is available because $S$ herself takes a certain attitude to $R: S$, if you will, accepts a commitment to conform her behavior to R' (G\&W 2009, 55). Read most naturally, G\&W claim, accepting a commitment to conform one's behavior to $R$ means simply that $R$ plays a role in one's motivation for what she does. But then an intuitive conception of what it is for an agent to be motivated yields a problem for the idea that belief is essentially ruleguided.

To see this, the idea of motivation by rules can be borne out in terms of practical reasoning. According to $\mathrm{G} \& \mathrm{~W}$, on a common view of motivation, an agent $S$ 's being motivated by a rule $R$ to form a belief $B$ must be able to be explained - at least partially - in terms of the role $R$ plays in $S$ 's practical reasoning (G\&W 2009, 55). That is, in saying that $S$ is motivated by $R$ to

\footnotetext{
${ }^{6}$ I will use 'following a rule' and 'being guided by a rule' interchangeably.
} 
form $B$, we must be able to appeal to a 'reasons-explanation' of $S$ 's forming $B$. (This reasonsexplanation need not involve any conscious practical inference on the part of $S$, just that she have some pro-attitude towards what is in accordance with $R$.)

G\&W suggest a belief-desire model of intentional explanation in order to sketch a model of the sort of practical reasoning $S$ would need to run through - whether consciously or subconsciously - in order to be motivated by $R$. Such a model, G\&W claim, would minimally need to involve something like the following practical inference on the part of $S$ :

$\left(\mathrm{P}_{1}\right)$ I want to believe what is in accordance with $R$.

$\left(\mathrm{P}_{2}\right)$ To believe that $p$ is in accordance with $R$.

(C) I want to believe that $p .^{7}$

The problem is that, as expressed in $\left(\mathrm{P}_{2}\right)$, the agent is required to form a further belief: the belief that to believe that $p$ is in accordance with $R$. According to the normativist, this further belief must itself be motivated by a rule if it is to count as a belief, properly construed. That is, in order to tell a story about how the agent is motivated to have this further belief, we need:

$\left(\mathrm{P}_{3}\right)$ I want to believe that (to believe that $p$ is in accordance with $R$ ).

But then we need a further belief to fill the 'doxastic slot':

$\left(\mathrm{P}_{4}\right)$ To believe that (to believe that $p$ is in accordance with $R$ ) is in accordance with $R$.

Since $\left(\mathrm{P}_{4}\right)$, too, expresses a belief, the normativist must tell a story about how the agent is motivated to have it:

$\left(\mathrm{P}_{5}\right)$ I want to believe that (to believe that (to believe that $p$ is in accordance with $R$ ) is in accordance with $R$ ).

But then we need yet another belief:

$\left(\mathrm{P}_{6}\right)$ To believe that (to believe that (to believe that $p$ is in accordance with $R$ ) is in accordance with $R$ ) is in accordance with $R$.

So we need:

$\left(\mathrm{P}_{7}\right)$ I want to believe that (to believe that (to believe that (to believe that $p$ is in accordance with $R$ ) is in accordance with $R$.

\footnotetext{
${ }^{7}$ This model is first introduced in Glüer and Pagin (1999).
} 
And so on ad infinitum. A vicious infinite regress ensues. ${ }^{8}$

\section{The Non-Intentional View of Rule-Following}

Before rejecting an appeal to 'blind' rule-following as a potential way out of the regress of motivations, G\&W first consider an alleged analogy between the regress of motivations and a regress argument Wittgenstein (1953) considers in Philosophical Investigations (PI). According to them, Wittgenstein's regress argument is importantly different from the regress of motivations, in that the former is a regress of interpretations. An interpretation, for Wittgenstein, is the substitution of one 'expression' (Ausdruck) of a rule for another (PI, §201). But if rulefollowing is always a matter of interpretation, then in order to follow a rule $R_{1}$ in some particular case, the rule-follower would need to apply another rule $R_{2}$ in order to determine what following $R_{1}$ amounts to in that case. But then she would need to apply yet another rule $R_{3}$ in order to determine what following $R_{2}$ amounts to in that case, and then another rule $R_{4}$ in order to determine what following $R_{3}$ amounts to in that case, and so on ad infinitum.

As is well-known, Wittgenstein's solution to the regress of interpretations seems to be that of abandoning the idea that rule-following is always a matter of interpretation and instead appealing to the notions of training, custom, and practice. According to G\&W $(2009,58)$, the notion of a practice will not help us out of the regress of motivations because a practice is simply a regularity in action, and it therefore cannot secure the following/conformity distinction. (What secures this distinction, after all, is an intentional condition - but given that a practice is simply a regularity in action, an appeal to the notion of a practice does not seem to leave room for such a condition.) Thus, G\&W conclude, Wittgenstein's solution to the regress of interpretations cannot also be a solution to the regress of motivations: the two arguments are not analogous.

Now, G\&W explicitly reject an appeal to 'blind' rule-following, suggesting that it might tempt us into philosophical quietism:

In response to [Wittgenstein's regress of interpretations], it has been suggested that there is a form of rule-

following that does not involve any sense of intentionally conforming to the rule: blind rule-following.

\footnotetext{
${ }^{8} \mathrm{G} \& \mathrm{~W}$ suggest that the regress of motivations argument not only poses a fundamental problem for normativism, but also for 'the very idea of general rules for reasoning, be they epistemic rules, or whatever' (2009, 56, italics in original). This is troublesome for those normativists who hold that 'objective' norms like (Truth) cannot guide belief formation directly - that they can only guide belief formation indirectly, via the 'subjective' epistemic norms (Shah and Velleman 2005, 519-20; Boghossian 2005, 101). Moreover, this indirect guidance approach is arguably the most plausible line of response to G\&W's no guidance argument (cf. Toppinen 2015, 398-402). But the regress of motivations argument, if sound, seems to undermine the indirect guidance approach. For, to follow the epistemic norms via which (Truth) purportedly guides us would be to set us on an infinite regress.
} 
Blind rule-following does not involve any intentional condition, and yet is supposed to be a genuine species of rule-following, distinct from mere brute reactions [...] Giving up on the intentional condition on ruleguidance, however, brings us back to square one. There must, we said, be a substantive distinction between mere accordance with a rule, mere regularity, and genuine rule-guidance. How is this distinction to be substantiated once we give up on the most natural and intuitive understanding of it? A quietist refusal to answer this question [...] cannot but fail to be persuasive in this context. After all, the intuitive, intentional condition appears to be satisfied in all uncontroversial cases of rule-guidedness. Giving it up in precisely the controversial cases, cases to do with intentional states and their contents, would seem to be a perfectly ad hoc move, simply intended to save a normativist theory under severe pressure. If belief normativism requires endorsing quietism about rule-guidance, so much the worse for belief normativism (G\&W 2013, 96; cf. G\&W 2010b, 160-64).

G\&W rightly point out that an appeal to a non-intentional view of rule-following - a view of rule-following which involves no intentional condition of the sort mentioned in (Guidance) above - simply takes us back so square one, since it fails to accommodate the distinction between genuine rule-guidance and simple conformity. G\&W appear to follow Boghossian $(2008,2012)$ in identifying blind rule-following with a rejection of the 'intentional view': the view that accepting a rule 'consists in an intentional state with general (prescriptive) content' (Boghossian 2008, 494). The conception of blind rule-following as contrasting with an intentional view of rule-following stems in part from a reading of PI 219 :

\footnotetext{
“All the steps are really already taken" means: I no longer have any choice. The rule, once stamped with a particular meaning, traces the lines along which it is to be followed through the whole of space. - But if something of this sort really were the case, how would it help me?

No; my description made sense only if it was to be understood symbolically. - I should say: this is how it strikes me.
}

When I follow the rule, I do not choose.

I follow the rule blindly.

According to Boghossian, what this passage suggests is that 'rule acceptance cannot consist in the formation of a propositional attitude in which the requirements of the rule are explicitly encoded' - blind rule-following contrasts with a picture of rule-following according to which 'rule-following is always fully sighted, always fully informed by some recognition of the requirements of the rule being followed' (Boghossian 2008, 495). In effect, therefore, Boghossian (and likewise G\&W) identifies blind rule-following with a rejection of an intentional condition on rule-guidedness.

\section{Blind Rule-Following}


As noted, Wittgenstein's solution to the regress of interpretations seems to be that of abandoning the idea that rule-following is always a matter of interpretation. According to an alternative reading of PI $\$ 219$, 'blind' contrasts not with 'intentional' but with 'based on interpretation': in saying that some rule-following is blind, we are saying that some rule-following is not based on the interpretation of the rule; we are not saying that rule-following involves no intentional condition. ${ }^{9}$ John McDowell writes:

Wittgenstein's concern is to exorcize the insidious assumption that there must be an interpretation that mediates between an order, or the expression of a rule given in training, on the one hand, and an action in conformity with it, on the other. In his efforts to achieve this, he is led to say such things as "I [follow] the rule blindly" (McDowell 1984, 239).

Likewise, here is Alex Miller:

When Wittgenstein speaks of rule-following as 'blind', 'blind' does not contrast with 'intentional' (as in Boghossian's reading). Wittgenstein is not arguing that acceptance of a rule is not an intentional state. Rather, 'blind' contrasts with 'based on interpretation'. To say that following a rule is ultimately blind is to say that at the fundamental level following a rule is not based on interpretation (Miller 2015, 411).

Thus, if this reading of Wittgenstein is correct, then G\&W are mistaken in claiming that blind rule-following does not involve any sense of intentionally conforming to the rule. Acceptance (or internalisation) of a rule still consists in an intentional state; we have only eschewed interpretation of it. Importantly, rule acceptance must be underpinned by training, custom, or practice: the rule does not simply cause the rule-follower to be in the relevant motivational state; rather, it figures in a rationalistic explanation of her action. Wittgenstein gives the example of following the instructions of a signpost:

Let me ask this: what has the expression of a rule - say a signpost - got to do with my actions? What sort of connection obtains here? - Well, this one, for example: I have been trained to react in a particular way to this sign, and now I do so react to it.

But with this you have pointed out only a causal connection; only explained how it has come about that we now go by the signpost; not what this following-the-sign really consists in. Not so; I have further indicated that a person goes by a signpost only in so far as there is an established use, a custom (PI §198).

Thus, one can follow a rule only insofar as she has been trained, or initiated into the custom or practice, of obeying its requirements.

\footnotetext{
${ }^{9}$ Key passages in Wittgenstein include, among others: PI §201, §206, §228, §506, and Zettel §277.
} 
Now it seems to me that Wittgenstein's solution to the regress of interpretations likewise allows us to block the regress of motivations. Suppose that $S$ accepts some rule $R$. $R$ might be (Truth), or one of the epistemic norms. ${ }^{10}$ And suppose further that, having been trained or initiated into the custom or practice of forming beliefs in accordance with $R, S$ 's acceptance of $R$ consists in an intentional state with $R$ as (part of) its content. ${ }^{11}$ The problem was that the second premise $\left(\mathrm{P}_{2}\right)$ in $\mathrm{G} \& \mathrm{~W}$ 's practical syllogism above expresses a belief, which according the normativist must itself be motivated by a further rule. But it seems to me that abandoning the idea that rule-following is always a matter of interpretation does not allow the regress to start. For it seems that belief formation can be motivated by rule acceptance (at least when acceptance of the rule is underpinned by training, practice, and custom). We can think of $S$ 's causal transactions with $R$ along the lines of one's causal transactions with the signpost: having been appropriately trained to react to the rule in a particular way, we do so when we find ourselves in a situation in which the need arises to invoke it; there need not be any further rule which mediates between acceptance of the rule and some performance. Having accepted $R$, the agent as a result of her training or practice - forms the higher-order belief expressed by $\left(\mathrm{P}_{2}\right)$. And this higher-order belief, when combined with $R$, causes her to be in the motivational state - the state of believing that $p$. In other words, there is no justification for $S$ 's believing that believing that $p$ is in accordance with $R: S$ can move from $\left(\mathrm{P}_{1}\right)$ and $\left(\mathrm{P}_{2}\right)$ to $(\mathrm{C})$ without the need for $\left(\mathrm{P}_{3}\right)$, $\left(\mathrm{P}_{4}\right),\left(\mathrm{P}_{5}\right)$, and so on (more on this below). As Wittgenstein metaphorically remarks:

[A]ll we do is read the lips of the rule and act, without appealing to anything else for guidance (PI §228).

And if this is right, then $S$ need not appeal to anything over and above $R$ itself in order to be motivated to form the belief that $p$.

To make the point explicit, let us briefly draw an analogy between the regress of motivations and a regress argument put forward by Boghossian (2008, 2012). Boghossian argues that five propositions form an inconsistent set:

(1) Rule-following is possible.

(2) Following a rule consists in acting on one's acceptance (or internalisation) of a rule.

${ }^{10}$ As noted above (fn. 8), some philosophers think that (Truth) can only guide belief formation indirectly, via the 'subjective' epistemic norms.

${ }^{11}$ To be clear: to say that accepting or internalising a rule is an intentional state is not to say that it is a conscious or explicit mental process. Intuitively, a native speaker accepts or internalises the syntax and grammar of her language, but she does not explicitly consider any rules when she conjugates a verb - she just does it. 
(3) Accepting a rule consists in an intentional state with general (prescriptive or normative) content.

(4) Acting under particular circumstances on an intentional state with general (prescriptive or normative) content involves some sort of inference to what the content calls for under the circumstances.

(5) Inference involves following a rule.

Propositions (1)-(5) together seem to set us on a vicious infinite regress. To see this, suppose we have the rule

(Email) Answer any email that calls for an answer immediately upon receipt!

In order to follow (Email), I will need an intention to conform to the rule's instructions. For example:

(Intention) For all $e$ : If $e$ is an email and you have just received $e$, answer it immediately!

But then I will need a belief to the effect that (Intention)'s antecedent is satisfied:

(Belief) $e$ is an email I have just received.

Now, (Intention) combined with (Belief) gives us what Miller (2015) calls an action-guiding state (AGS):

(AGS) Answer $e$ immediately!

Rule-following, then, would always seem to require inference on the part of the rule-follower - in this case an inference from (Intention) and (Belief) to (AGS). But according to Boghossian, inference is an example of rule-following par excellence, and so we are set on an infinite regress. For in following (Email), I am relying on a general rule of inference, in this case an imperatival equivalent to the modus ponens rule:

(MP*) From 'If $C$, do $A$ ' and $C$, conclude 'do $A$ '!

But then if it is true that rule-following requires an intention of the part of the rule-follower to comply with the instructions of any given rule, then following (MP*) itself would require an intention with the rule as (part of) its content, along with an inference from the belief that its antecedent is satisfied, to the action-guiding state. But then we are set on a vicious regress: 'inference rules whose operation cannot be captured by the intention-based model are presupposed by that model itself' (Boghossian 2012, 41). 
So, it looks like one of Boghossian's five propositions must go. Denying (1) would amount to rule-following scepticism (cf. Kripke 1982). (2) and (4) seem hard to deny, and (3) is just the intentional view that gives us the intentional condition mentioned in (Guidance) above the condition that secures the following/conforming distinction. And (5), according to Boghossian, 'seems analytic of the very idea of deductive inference' $(2012,42){ }^{12}$

Now according to Miller (2015), an appeal to the notion of blind rule-following (where 'blind' contrasts with 'based on interpretation' rather than 'intentional') stops Boghossian's regress in its tracks. For we can say that $S$ follows (Email) blindly, without interpretation of the rule. If rule-following required interpretation, then when asked for a reason or justification why $S$ answered $e$ immediately upon receipt, she would have to cite the further rule (MP*) along with her belief that its antecedent conditions obtain. But $S$ need not provide such a justification or reason: all she can say is this is simply what I do (PI §217). ${ }^{13}$ We can say that $S$ has been trained, or initiated into the custom or practice, of answering emails immediately upon receipt. $S$ 's acceptance or internalisation of (Email) itself is what motivates her doing so; she need not apply (MP*). So, Miller suggests the following modification to Boghossian's proposition (4):

(4*) Acting under particular circumstances on an intentional state with general (prescriptive or normative) content involves some sort of rule-mediated transition to what the content calls for under the circumstances (Miller 2015, 408).

Hence, Boghossian's regress does not get off the ground: even if inference involves following a rule, $S$ need not apply (MP*) in order to follow (Email). (Granted, $S$ coincidentally conforms to $\left(\mathrm{MP}^{*}\right)$ when she follows (Email), but she is not being guided by it, since she has an intentional state with (Email) - and not (MP*) - as its content.)

My suggestion is that, if abandoning the idea that rule-following is always a matter of interpretation stops Boghossian's regress in its tracks, then it likewise stops the regress of motivations in its tracks. As per $\left(4^{*}\right)$, we can say that $S^{\prime}$ s acceptance or internalisation of $R$ is what motivates her belief that $p$; she can move from $\left(\mathrm{P}_{1}\right)$ and $\left(\mathrm{P}_{2}\right)$ to $(\mathrm{C})$ without the need for a further application of $R$ - without the need for $\left(\mathrm{P}_{3}\right),\left(\mathrm{P}_{4}\right),\left(\mathrm{P}_{5}\right)$, and so on. $S$ cannot cite any justification or reason for her taking $R$ to require of her that she believes that believing that $p$ is in accordance

\footnotetext{
${ }^{12}$ In order to avoid the regress, Boghossian suggests rejecting (3), equating a non-intentional view of rulefollowing with blindness in Wittgenstein's discussion. On the other hand, G\&W suggest rejecting (5), since they do not share the intuition that inference involves following a rule (G\&W 2010b, 163; cf. Wright 2012).

${ }^{13}$ Miller's point is not that there is no justification or reason for accepting (Email). We can presumably cite many reasons for accepting (Email). Rather, the point is that there is no justification or reason for my taking (Email) to require of me that I answer $e$ immediately upon receipt (Miller 2015, 412).
} 
with $R$. She believes that believing that $p$ is in accordance with $R$ because she has been trained, or initiated into the custom or practice, of invoking $R$ when the need arises.

I have said that $S$ cannot cite any justification or reason for her taking $R$ to require of her that, in moving from $\left(\mathrm{P}_{1}\right)$ and $\left(\mathrm{P}_{2}\right)$ to $(\mathrm{C})$, she forms the higher-order belief expressed by $\left(\mathrm{P}_{2}\right)-$ the belief that believing that $p$ is in accordance with $R$. In more recent work, Boghossian suggests that a proper account of inference must accommodate a 'taking condition':

(Taking Condition) Inferring necessarily involves the thinker taking his premises to support his conclusion and drawing his conclusion because of that fact (Boghossian 2014, 5).

Whether taking is a (partial or outright) belief, an intuition, an irreducible, sui generis state or something else entirely - is a matter of some controversy. ${ }^{14}$ We need not delve into this debate here. Instead, regardless of what taking consists in, I want to suggest that the normativist should reject (Taking Condition). For doing so is complementary to the idea that rule-following is fundamentally blind in the Miller/McDowell sense: $S$ need not be able to cite any justification or reason for her taking $R$ to require of her that she believe that believing that $p$ is in accordance with $R$ - she just forms that belief without 'taking' it to support the conclusion (C). ${ }^{15}$ So, without the threat of regress, the normativist can say that $S$ follows $R$ blindly, without interpretation of the rule: she moves from $\left(\mathrm{P}_{1}\right)$ and $\left(\mathrm{P}_{2}\right)$ to $(\mathrm{C})$ without the need for a further application of $R$. Thus, an appeal to blind rule-following blocks the regress of motivations.

To conclude, recall that G\&W reject the thought that the rule-following considerations provide a way out of the regress of motivations precisely because Wittgenstein's regress is one of interpretations. Wittgenstein appeals to the notion of a practice; but since a practice is a mere regularity, G\&W maintain, such an appeal fails to accommodate the distinction between genuine rule-guidance and mere conformity. G\&W claim that a 'quietist refusal' to answer the question of what secures this distinction is unpersuasive. But the present account suggests no such appeal. G\&W are right to point out that a practice is a regularity; but it is not a mere regularity: it is a regularity underpinned by an intentional condition to comply with the instructions of a rule. Since we preserve our intentional condition, appealing to the notion of a practice accommodates the following/conforming distinction. Blind rule-following (where 'blind' contrasts with 'based on interpretation' rather than 'intentional'), therefore, should not tempt us

\footnotetext{
${ }^{14}$ A survey of some of these views, along with a critique of (Taking Condition), can be found in McHugh and Way (2016).

${ }^{15}$ Valaris (2017) argues that (Taking Condition) is in tension with the rule-following picture of inference. If the foregoing is correct, the normativist should be sympathetic to that picture (cf. fn. 12).
} 
into quietism, since we can still say something informative about the following/conforming distinction: we can say that the distinction is secured by an intentional condition to comply with the instructions of the rule. And this is not to say that acceptance of a rule is a conscious mental process: just as one comes to accept certain rules when learning the grammar and syntax of her language, one comes to accept certain rules when being trained or initiated into the custom or practice of forming beliefs.

\section{Acknowledgements}

Thanks to Alex Miller for much useful feedback and discussion on previous drafts of this paper, and to an anonymous referee for useful suggestions. This publication was made possible by a University of Otago postgraduate publishing bursary.

\section{References}

Boghossian, P.A. 2005 [2008]. “Is Meaning Normative?” In Content and Justification: Philosophical Papers, 95-107. Oxford: Clarendon Press.

Boghossian, P.A. 2008. "Epistemic Rules." The Journal of Philosophy 105 (9): 472-500.

Boghossian, P.A. 2012. "Blind Rule-Following." In Mind, Meaning, and Knowledge: Essays on Themes from the Philosophy of Crispin Wright, edited by Annalisa Coliva, 27-48. Oxford: Oxford University Press.

Boghossian, P.A. 2014. "What is Inference?" Philosophical Studies 169 (1): 1-18.

Bykvist, K., and A. Hattiangadi. 2007. "Does Thought Imply Ought?" Analysis 67 (4): 27785.

Bykvist, K., and A. Hattiangadi. 2013. "Belief, Truth and Blindspots." In The Aim of Belief, edited by T. Chan, 100-122. Oxford: Oxford University Press.

Engel, P. 2013. "In Defence of Normativism about the Aim of Belief." In The Aim of Belief, edited by T. Chan, 31-62. Oxford: Oxford University Press.

Fassio, D. 2011. "Belief, Correctness and Normativity." Logique et Analyse 54 (216): 471-86.

Gibbard, A. 2012. Meaning and Normativity. Oxford: Oxford University Press.

Glüer, K., and P. Pagin. 1999. "Rules of Meaning and Practical Reasoning." Synthese 117 (1): 207-27.

Glüer, K., and ̊̊. Wikforss. 2009. "Against Content Normativity.” Mind 118 (469): 31-70.

Glüer, K., and Å. Wikforss. 2010a. "The Truth Norm and Guidance: A Reply to Steglich-Petersen." Mind 119 (475): 757-61.

Glüer, K., and A. Wikforss. 2010b. "Es braucht die Regel nicht: Wittgenstein on Rules and Meaning." In The Later Wittgenstein on Language, edited by D. Whiting, 148-66. Basingstoke: Palgrave Macmillan.

Gluier, K., and $\AA$. Wikforss. 2013. "Against Belief Normativity.” In The Aim of Belief, edited by T. Chan, 80-99. Oxford: Oxford University Press.

Glüer, K., and Å. Wikforss. 2015. "Still No Guidance: Reply to Steglich-Petersen." Theoria 81 (1): $272-79$.

Greenberg, A. 2018. "Should I Believe All the Truths?" Synthese. Published online: https://doi.org/10.1007/s11229-018-1882-9.

Hlobil, U. 2015. “Anti-Normativism Evaluated." International Journal of Philosophical Studies 23 (3): 376-95. 
Jarvis, B.W. 2012. "Norms of Intentionality: Norms That Don't Guide.” Philosophical Studies 157 (1): 1-25.

Kalantari, S.A., and M. Luntley. 2013. "On the Logic of Aiming at Truth." Analysis 73 (3): 419-22.

Kripke, S.A. 1982. Wittgenstein on Rules and Private Language. Oxford: Blackwell.

McDowell, J. 1984 [1998]. "Wittgenstein on Following a Rule." In Mind, Value and Reality, 221-62. Cambridge: Harvard University Press.

McDowell, J. 1993 [1998]. "Meaning and Intentionality in Wittgenstein's Later Philosophy." In Mind, Value and Reality, 263-78. Cambridge: Harvard University Press.

McHugh, C., and J. Way. 2016. "Against the Taking Condition." Philosophical Issues 26 (1): 314-31.

Miller, A. 2014. "Wittgenstein, Quine and Dummett on Conventionalism about Logic." Thought: A Journal of Philosophy 3 (4): 292-301.

Miller, A. 2015. "Blind Rule-Following and the "Antinomy of Pure Reason." The Philosophical Quarterly 65 (260): 396-416.

Miller, A. 2017. "Rule-Following, Meaning and Primitive Normativity." Mind 128 (511): 73560 .

Nolfi, K. 2015. "How to Be a Normativist about the Nature of Belief." Pacific Philosophical Quarterly 96 (2): 181-204.

Raleigh, T. 2013. "Belief Norms and Blindspots." The Southern Journal of Philosophy 51 (2): 243-69.

Shah, N., and J.D. Velleman. 2005. "Doxastic Deliberation." The Philosophical Review 114 (4): 497-534.

Steglich-Petersen, A. 2010. "The Truth Norm and Guidance: A Reply to Glüer and Wikforss." Mind 119 (475): 749-55.

Steglich-Petersen, A. 2013. "The No Guidance Argument." Theoria 79 (1): 279-83.

Swindlehurst, Z.M. 2020 “The Knowledge Norm of Belief." Thought: A Journal of Philosophy 9 (1): 43-50.

Toppinen, T. 2015. "How Norms (Might) Guide Belief." International Journal of Philosophical Studies 23 (3): 396-409.

Tracy, E.V. 2019. "Unfollowed Rules and the Normativity of Content." Analytic Philosophy. Published online: https://doi.org/10.1111/phib.12159.

Valaris, M. 2017. "What Reasoning Might Be.” Synthese 194 (6): 2007-24.

Wedgwood, R. 2002. "The Aim of Belief." Philosophical Perspectives 16 (1): 267-97.

Wedgwood, R. 2013. “The Right Thing to Believe.” In The Aim of Belief, edited by T. Chan, 123-39. Oxford: Oxford University Press.

Whiting, D. 2010. "Should I Believe the Truth?” Dialectica 64 (2): 213-24.

Williams, B. 1973. "Deciding to Believe." In Problems of the Self, 136-50. Cambridge: Cambridge University Press.

Wittgenstein, L. 1953 [2009]. Philosophical Investigations. Translated by G.E.M. Anscombe, P.M.S. Hacker, and J. Schulte. 4th Edition. Oxford: Blackwell.

Wittgenstein, L. 1967 [1981]. Zettel. Translated by G.E.M. Anscombe. 2nd ed. Oxford: Blackwell.

Wright, C. 2012. "Replies Part I: The Rule-Following Considerations and the Normativity of Meaning." In Mind, Meaning and Knowledge: Essays on Themes from the Philosophy of Crispin Wright, edited by A. Coliva, 379-401. Oxford: Oxford University Press. 